\title{
Changing the face of academic skills workshops
}

\author{
Sheryl Mansfield \\ University of Northampton
}

\section{Abstract}

The flipped approach offers flexibility in the way students learn and was adopted within Learning Development workshops to improve academic skills. Academic skills are predominantly taught using passive content, however the flipped approach looks to change the emphasis and provide active opportunities to understand taught knowledge. The sessions were delivered alongside self-paced online, asynchronous content to scaffold academic skills and feed-forward guidance to inform summative assessment preparation. The objective was to assess the effectiveness of the flipped approach in delivering academic skills. A cohort of 50 first year students completed three face-to-face academic skills sessions together with the asynchronous content. Each were themed to develop different academic skills using subject specific examples. Attendance data was collected and a survey was used to evaluate the asynchronous content and measure the self-perceived academic confidence levels of students. To measure the success of the flipped approach this data was analysed together with the number of attempts at each e-tivity and the formative and summative grades. Results demonstrated those who attended two or more sessions $(57.7 \%+1.43)$ had a significantly higher summative score $(p=0.041)$ than those who attended 1 or less $(51.7 \%+2.73)$. The summative grades and the number of attempts at the asynchronous content demonstrated a positive linear relationship for e-tivity 1 to 3 . Overall the academic confidence improved in nearly a third of all students for each e-tivity and 17 students (54.8\%) stated that they preferred the flipped approach in developing their academic skills. This emphasises that the flipped approach is an effective method to improve summative grades and deliver academic skills.

Keywords: flipped classroom; active learning; academic skills; asynchronous. 


\section{Introduction}

Academic skills or study skills includes a range of different topics from "manage yourself" (Price and Maier, 2007), referencing (Hitch et al., 2012), to writing and thinking critically (Gunn et al., 2011). The development of these skills is fundamental for students' success in higher education (Blythman and Orr, 2002; MacVaughan et al., 2014). Thus, ensuring that academic skills are incorporated into modules is vital (Hill and Tinker, 2018) and doing so will improve learners' awareness of the expectations (Harwood and Hadley, 2004), especially at the start of a university course. Generally, academic skills sessions are taught face-to-face either in a workshop or during a one-to-one environment (Murray and Nallaya, 2016). This research looks to change the face of the academic skills workshop and offer different modes of interaction with academic skills material. It is hoped that this holistic approach of teaching academic skills will improve academic confidence in students and offer guidance for learning at Level 4 and beyond (Hill and Tinker, 2018). Although research highlights that academic skills content will work best if presented with subject specific content (Appleton, 2005) there is limited research highlighting the most effective pedagogical approach to use (Munn and Small, 2017).

This research project evaluates subject specific academic skills sessions using the flipped approach and its effectiveness. A detailed plan was proposed in collaboration with a Learning Development tutor and the subject team to incorporate the sessions in accordance with the assessments and learning objectives of the module. A series of face-to-face sessions totalling two hours and asynchronous activity was designed to enhance academic skills development. The main objective for this approach was to address the lack of understanding in the fundamental basics of academic writing which included formal writing style, structure and use of evidence. The approach was chosen to allow exploration of the knowledge learned in the asynchronous content by completing practical activities face-to-face. The research involved a vocational subject area with practical based learners within the Faculty of Health and Society. It was hoped that the research would also extend to improving achievement grades in the assessment. Defining the reason for non-achievement is beyond the scope of this article. 
However, the link between academic confidence and performance has been explored using self-efficacy perceptions.

\section{Flipped Classroom}

The benefit of the flipped approach allows students to explore the content learnt prior to the classroom and examine these concepts in a student-centred environment. Bergmann and Sams (2007) cited an advantage of this approach: time within the classroom can be given to guiding and practising the knowledge. This can promote an environment which allows students to regulate their own learning and be independent learners (Lage et al., 2000; Bergmann and Sams, 2007; Wilson, 2013) which is important for academic skills development. The methodology of this research used a flipped approach with students completing previews of content before attending face-to-face sessions. The face-to-face sessions were active and used to effectively problem-solve, discuss, and complete interactive classroom activities (Hao, 2016), blending the online content into a practical format. Carr et al. (2015) emphasise that active learning is a very broad concept related to an extensive range of learning strategies. This approach moves the information transition outside the classroom, supporting the session with activities for active and social learning, and utilising pre- or postclassroom activities (Abeysekera and Dawson, 2014). This concept allowed the Learning Development tutor to support the learning process within the classroom rather than just dispensing knowledge. hooks' (2010) chapter 'To lecture or not' outlines that misunderstandings can occur within large lectures as listeners often project what they heard rather than what was said.

This flipped classroom content was in the form of structured e-tivities using Padlet and Xerte software. E-tivities are scalable tasks that can be found on a range of different platforms (Salmon, 2013). The PADLET resource was used to enable collaboration within the class: the features of the software allow small groups to produce a multimedia post improving engagement in an activity (Garnham and Betts, 2018). Fisher (2017) promotes that the anonymity allows students to feel more comfortable contributing to discussions in the form of a written post. The Xerte was used to create interactive e-tivities due to its accessibility which 
is integrated into the software (van Hoorebeek et al., 2009). Xerte is an open source suite of tools (Koohang et al., 2011) developed in 2008 by the University of Nottingham. The browserbased tools allowed learning materials to be developed quickly and easily (University of Nottingham, 2008) and offered a range of interactive designs. Content was developed to ensure that students interacted with the knowledge taught to help promote recall (Rice et al., 2019). For example, using drag and drop activities within the software as a mini formative assessment.

\section{Academic confidence}

Measuring undergraduate confidence is problematic, measuring academic skills confidence at Level 4; when the expectations are ambiguous is even harder. Bandura (1997) defines selfefficacy as one way of defining beliefs of a person's competence. Using this definition and relating it to an academic context could help to define the term academic confidence. Previous studies support that students' self-efficacy beliefs about their capabilities influence their academic achievement (Bandura, 1977). Bartimote-Aufflick et al. (2016) discussed selfefficacy in an academic environment as having a strong association with outcomes of students (Mattern and Shaw, 2010). Valentine et al. (2004) suggested that educational outcomes and attitude could be shaped by a self-exploration of feelings and beliefs. Conversely, research has shown that students are often poor at predicting their own ability (Dunning et al., 2004; Chevalier et al., 2009; Price et al., 2011) as similar skills are required to judge their own performance as to succeed (Hacker et al., 2000). There are obvious issues which are inherent with the nature of self-assessment (Falchikov and Boud, 1989,). Yet Nicholson et al. (2013) maintain that students who are confident in their own ability will perform better and take responsibility for their own learning (Ryan and Deci, 2000). Allowing opportunities at institutions to engage in self-assessment of academic skills could be helpful to improve success (Reed et al., 2011). Measuring the self-efficacy perceptions could be a useful tool for students to clarify their ability. Price et al. (2011) advocate that academic skills should be pre-tested, prior to any instruction, to act as a stimulus for increased engagement and to promote additional skill-building opportunities once a skill deficit has been identified. To understand the impact of the flipped approach on students' academic confidence, this method 
was adopted and levels of perceived academic confidence pre and post sessions were measured.

\section{Methods}

\section{Procedure}

A cohort of 50 first year students completed three academic skills sessions in addition to the content for a module (Table 1). The first 30-minute face-to-face session delivered within the first week introduced the support offered at the institution with regards to academic skills and then introduced the PADLET task in preparation for the subsequent sessions. The session informed the cohort how to access the on-line task and defined the small group activity required. This linked to reading an article and placing a reflection onto a PADLET. The e-tivity content was also introduced, and an expectation given that these were to be complete before the second face-to-face session. The second 60-minute face-to-face session in week two reflected on the e-tivities and developed skills to build an effective argument using the reflections gathered on the PADLET. All content delivered (online and face-to-face) was designed to support the formative and summative assessments. The final 30-minute face-toface session in week five focussed on feedback from the formative assessments to feedforward information to support the summative assessment. 
Table 1. A table outlining the flipped delivery completed in the research.

\begin{tabular}{|c|c|c|c|c|c|}
\hline Content & Week 1 & Week 2 & \multirow{3}{*}{ 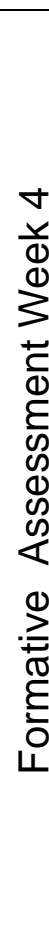 } & Week 5 & \multirow{3}{*}{ 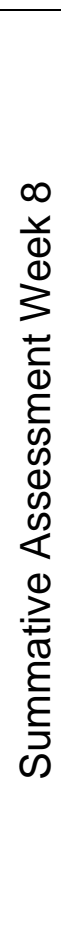 } \\
\hline Asynchronous & $\begin{array}{l}\text { Post session } \\
\text { activity completed } \\
\text { as group work to } \\
\text { reflect on an article } \\
\text { using PADLET. }\end{array}$ & $\begin{array}{l}\text { Pre-learning e-tivities } 1 \\
\text { to } 5 \text { to support face-to- } \\
\text { face session. }\end{array}$ & & $\begin{array}{l}\text { E-tivities } 1 \text { to } 5 \text { still } \\
\text { available for } \\
\text { repeated attempts. }\end{array}$ & \\
\hline Face-to-face & $\begin{array}{l}\text { Learning } \\
\text { Development } \\
\text { introduction and } \\
\text { skills used to read } \\
\text { an article ( } 30 \\
\text { minutes). }\end{array}$ & $\begin{array}{l}\text { Session incorporated } \\
\text { activities on structure, } \\
\text { academic writing and } \\
\text { building an effective } \\
\text { argument (60 } \\
\text { minutes). }\end{array}$ & & $\begin{array}{l}\text { Feedback session } \\
\text { to feed forward to } \\
\text { the summative } \\
\text { assessment ( } 30 \\
\text { minutes). }\end{array}$ & \\
\hline
\end{tabular}

The asynchronous e-tivities were designed using the versatile and interactive content of the Xerte Toolkit 2.0. These were designed as five e-tivities which incorporated formative assessments within tasks to check understanding. They were themed into developing different academic skills and the content written demonstrated subject specific examples.

These included e-tivity 1: time management, e-tivity 2: assessment structure, e-tivity 3: writing an essay, e-tivity 4: writing a paragraph, and e-tivity 5: notetaking. These were presented as a separate learning unit within the module's virtual learning environment. To allow freedom in accessing each e-tivity they were not aligned sequentially, and all were made available to complete at the same time. Attempts were unlimited to allow students to access the content throughout the module. The number of attempts were recorded to help identify if there was a relationship with perceived academic confidence. On the first page of each e-tivity a clear outline and an approximate time in minutes were listed to help highlight the knowledge and length of time it would take to complete. 
Figure 1. Taken from Writing an Essay Xerte demonstrating the interactive content to ensure that learners are actively learning content delivered within the asynchronous material.

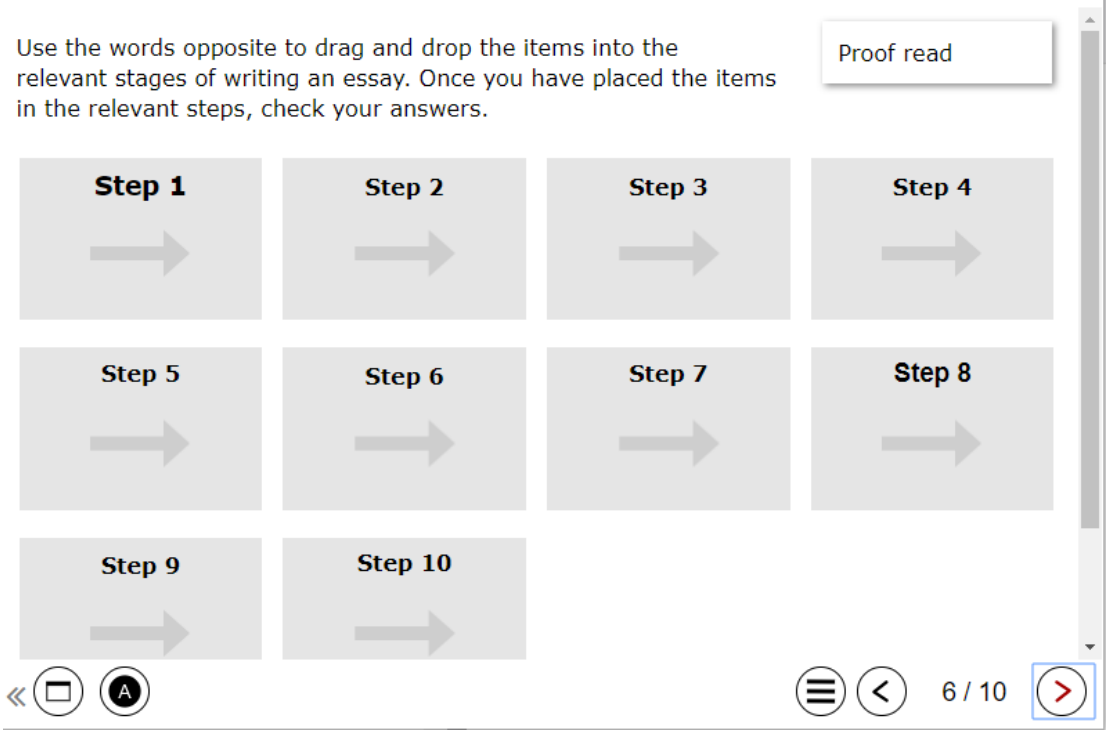

\section{Data analysis}

To define the success of the asynchronous component, performance data was analysed and evaluated. Data relating to the number of attempts and scores within the e-tivities from the cohort was recorded. The number of attempts at each e-tivity was divided into 3 categories: 0 attempts, 1-5 attempts, and 6+ attempts. All students who had attempted the content demonstrated a graded score for the formative elements within the e-tivity. All students with graded scores were counted as an attempt as there was evidence to suggest interaction with the e-tivity.

Student consent was given for the formative and summative grades to be analysed. This was used to measure the success of the asynchronous component and the flipped approach. After each face-to-face session attendance data was collected; attendance was categorised into attending two or more sessions or one or less. To measure the success of the approach this data was analysed together with the number of attempts at each e-tivity, self-reported academic confidence and the formative and summative grades. Results were evaluated to demonstrate an understanding of the benefits of the approach in academic skills delivery. 
A survey was used to evaluate the asynchronous content and measure the academic confidence levels of students utilising both qualitative and quantitative questions. No qualitative comments were made by the students on the survey. The survey was conducted within a workshop; students not in attendance were offered an online version to complete. A total of 31 students completed the survey (62\% response rate). Participation in the study was voluntary and the students who completed the survey had the option of having their data withdrawn from the research project upon request. The survey provided scores on students' academic confidence in the different academic skills abilities prior and post completion of asynchronous activity. The survey also asked students to provide preferred methods of developing academic skills and to evaluate the workshops and all e-tivities. The selfperceived academic confidence levels of students and summative grades were used to measure the success of the flipped approach in delivering academic skills.

\section{Results}

\section{Attendance}

As expected, those who attended more sessions achieved better results. Those who attended two or more sessions $(57.7 \%+1.43)$ had a significantly higher summative score than those who attended 1 or less $(51.7 \%+2.73),(48), t=2.102, p=0.041$ (Figure 2). Even though the students who attended two or more sessions had a higher formative grade the improvement to the summative grade was greater. This demonstrated a significant improvement from the starting point of each student and added value to the summative scores of those who attended. This emphasises that the flipped approach is effective at improving summative grades. 
Figure 2. Mean summative and formative grades for students who attended one or less face-to-face sessions and two or more face-to-face sessions.

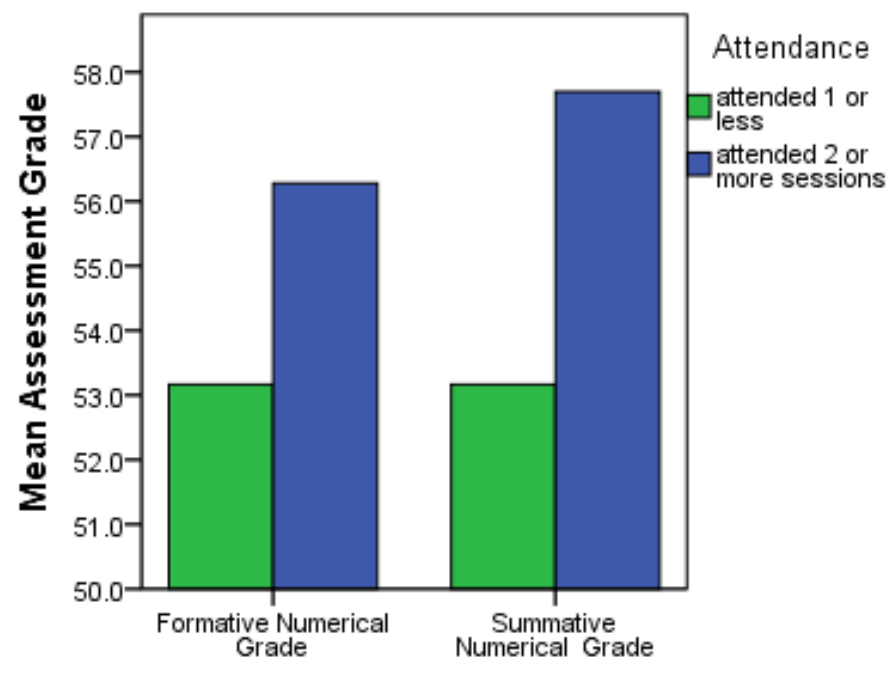

\section{Attempts at asynchronous content}

An overall total of 1,239 attempts were recorded for all five e-tivities. The majority of attempts $66 \%(n=818)$ were completed before the formative assessment date and $34 \%(n=421)$ of all attempts were completed between the formative and the summative assessment hand in date. This demonstrates that students reviewed the content to help inform their writing prior to and after the formative submission, thus acting to support the learning process for both the formative and summative assessments. Although the e-tivities lacked a sequential element the number of attempts declined as the e-tivities progressed. $35 \%$ of the total number of attempts were completed on e-tivity $1,28 \%$ on e-tivity $2,20 \%$ on e-tivity $3,9 \%$ on e-tivity 4 and $8 \%$ on e-tivity 5 .

\section{Impact on summative grade}

The number of attempts on each e-tivity and summative grade were investigated. For e-tivity 1 to 3 data showed a positive linear trend: as the number of attempts increased, the summative grades increased (Table 2). The last two e-tivities did not demonstrate the same pattern due to the decline in the number of attempts. For e-tivity 4 students with no attempts showed a mean summative grade of $53 \%(+/-9.42) n=12$; those with attempts between 1 to 5 
times showed a mean summative grade of $57.3 \%(+/ 9.5) n=35 ; 6+$ attempts showed a mean summative grade of $53 \%(+/-4.36) n=3$. For e-tivity 5 students with no attempts showed a mean summative grade of $54.9 \%(+/ 9.24) n=15$; those with attempts between 1 to 5 times showed a mean summative grade of $56.7 \%(+/ 9.57) n=34 ; 6+$ attempts showed a mean summative grade of $51 \% n=1$.

Table 2. Mean and standard deviation of the summative assessment grades and number of attempts for each e-tivity.

\begin{tabular}{|l|l|l|l|}
\hline Attempts & e-tivity 1 & $\begin{array}{l}\text { e-tivity 2 } \\
M(S D)\end{array}$ & $\begin{array}{l}\text { e-tivity 3 } \\
M(S D)\end{array}$ \\
\hline 0 & $\begin{array}{l}\text { M (SD) } \\
n=\%(4.70)\end{array}$ & $\begin{array}{l}50 \%(4.7) \\
\mathrm{n}=6\end{array}$ & $\begin{array}{l}50 \%(3.98) \\
\mathrm{n}=7\end{array}$ \\
\hline $1-5$ & $54.8 \%(3.09)$ & $54.3 \%(2.64)$ & $56.6 \%(1.95)$ \\
& $\mathrm{n}=14$ & $\mathrm{n}=17$ & $\mathrm{n}=26$ \\
\hline $6+$ & $57.8 \%(1.33)$ & $58.4 \%(1.36)$ & $57.6 \%(1.75)$ \\
& $\mathrm{n}=30$ & $\mathrm{n}=27$ & $\mathrm{n}=17$ \\
\hline
\end{tabular}

\section{Academic confidence}

The measure of self-perceived confidence before and after each e-tivity was measured to define if students' self-perceived academic confidence had improved. Each student was asked to rate themselves before and after each e-tivity using a five-point scale ( 1 = very poor, $3=$ average, 5 = excellent). The self-perceived academic confidence in each skill was recorded before and after each e-tivity, 62\% (31 students) completed the survey (Table 3). Overall the academic confidence improved in nearly a third of all students in each e-tivity. Caution should always be exercised when interpreting self-perceived ratings (Castells et al., 2015) especially when the sample size is small. However, the e-tivities have been shown to improve some students' academic confidence which highlights that the asynchronous content was effective. Students who perceived themselves as poor, average, and good all showed improvements demonstrating that a range of student abilities improved their academic skills. 
Table 3. The level of self-perceived confidence of students before each e-tivity and the percentage (number of students) who improved their confidence after each e-tivity.

\begin{tabular}{|c|c|c|c|c|}
\hline \multicolumn{1}{|c|}{$(\mathrm{n}=31)$} & $\begin{array}{c}\text { Did the } \\
\text { e-tivity improve } \\
\text { students' overall } \\
\text { confidence }\end{array}$ & $\begin{array}{c}\text { Student rated as poor } \\
\text { before e-tivity and } \\
\text { improved confidence } \\
\text { post e-tivity }\end{array}$ & $\begin{array}{c}\text { Student rated as } \\
\text { average before e- } \\
\text { tivity and improved } \\
\text { confidence post e- } \\
\text { tivity }\end{array}$ & $\begin{array}{c}\text { Student rated as } \\
\text { good before e-tivity } \\
\text { and improved } \\
\text { confidence } \\
\text { post e-tivity }\end{array}$ \\
\hline e-tivity 1 & $35.5 \%(n=11)$ & $25 \%(n=1)$ & $54.4 \%(6)$ & $26.7 \%(n=4)$ \\
\hline e-tivity 2 & $35.5 \%(n=11)$ & $60 \%(n=3)$ & $50 \%(n=4)$ & $22.2 \%(n=4)$ \\
\hline e-tivity 3 & $29 \%(n=9)$ & $33.3 \%(n=2)$ & $20 \%(n=2)$ & $35.7 \%(n=5)$ \\
\hline e-tivity 4 & $30 \%(n=9)$ & $33.3 \%(n=1)$ & $54.5 \%(n=6)$ & $14.3 \%(n=2)$ \\
\hline e-tivity 5 & $25.8 \%(n=8)$ & $100 \%(n=1)$ & $50 \%(n=5)$ & $15.4 \%(n=2)$ \\
\hline
\end{tabular}

The preferred methods of developing academic skills were recorded. Two students (6.5\%) stated asynchronous content only, 12 students (38.7\%) stated face-to-face only, and 17 students $(54.8 \%)$ stated a mixture of both. This suggests that students preferred the active pedagogy of the flipped approach to develop their academic skills.

\section{Discussion}

Bishop and Verleger (2013) define the flipped method as a two-part educational technique with interactive group learning activities inside the classroom, and direct computer-based content outside the classroom. This technique was adopted for the research as it had been suggested that students prefer this method to traditional lecturing formats (Lage et al., 2000; Strayer, 2012) which can only benefit academic skills teaching. In addition, this pedagogy offered to improve self-efficacy (Chyr et al., 2017) and encouraged students to take responsibly for their own studies and become independent learners. Although it is still ambiguous whether it is the flipped component or the active part of the classroom which causes this shift (Jenson et al., 2015) the method demonstrates higher learning experience satisfaction than the traditional lecture (Forsey et al., 2013; Baepler, Walker and Driessen, 2014). Using the active pedagogy of the flipped approach offered similar benefits as well as positively affecting academic achievement endorsed by other researchers (Lage et al., 2000; 
Bergmann and Sams, 2007; Chuthapisith, et al., 2009; Wilson, 2013). The academic skills knowledge in the flipped design allowed the opportunity for the students to ask questions of the content learnt asynchronously, in the classroom. This research agrees with the metaanalysis conducted by Jenson et al. (2015) who investigated student exam performance using the flipped learning method. Although vigilance should be taken when interpreting quantitative results from a meta-analysis (Fagard et al., 1996), exam results improved by $6 \%$ in sessions where students actively participated compared to those recorded in a traditional lecture style format (Jenson et al., 2015). Therefore, it can only be an advantage to use this method in academic skills teaching to demystify the expectations of writing at undergraduate level.

\section{Attendance}

This research concluded that students who attended two or more sessions had a $6 \%$ significantly higher summative score than those who attended one or less. Even though students who attended two or more sessions had a higher formative score the improvement to the summative score was greater in the group who attended two or more sessions. This significant difference in the summative grade emphasises the importance of attendance in the approach even though there were only two hours of face-to-face contact. The flipped method allowed the tutor to support the learning process within the classroom rather than just dispensing knowledge. Chen et al. (2014) commented that a collaborative experience is facilitated by changing the classroom from a passive lecture to one that utilises the flipped method. Students can perceive academic skills as predominately tutor led activity therefore it is advantageous to shift to an approach which will facilitate individual learner needs (Smith et al., 2012). Farmer (2018) endorses that the flipped approach will be more successful using passive content to complete an active task than one that relies on the dissipation of passive content. It also helped that the content used in the sessions were subject specific and designed to incorporate the assessment.

\section{Attempts at asynchronous content}

Isolating the number of attempts at each e-tivity compared to the summative grade did not demonstrate a significant difference which may have be due to the low number of participants 
within the study. However, the improvement which spans a grade boundary confirms that this approach in academic skills teaching could offer positive outcomes for students. The reason for the number of attempts improving the summative scores could have been due to the fact that students viewed the asynchronous content on a number of occasions in order to fully understand the knowledge. The number of attempts demonstrated that the students found value in the content which could have been for a number of reasons. Chuthapisith et al. (2009) demonstrated a significant difference in the higher retention performance and level of enjoyment in students using the Xerte and flashmacromedia when comparing students who received the same information via a leaflet. This helps to understand that the use of this type of media tool had advantages which could have been due to its interactivity in addition to the integrated formative assessments.

Previous research using online learning to develop academic skills demonstrated that students completed two to four attempts to ensure they answered the questions correctly (Gunn et al., 2011). This could justify the frequency of attempts for each student as each etivity had a series of formative assessment tasks. Large amounts of attempts could also be due to students wanting to recall the subject specific content as this was the main transition of academic skills knowledge rendering the classroom as the place to practically apply the content learnt from the e-tivities. However, the data capture from the software was limited as only the number of attempts completed and the last attempted performance score was recorded. Therefore, an attempt would be registered once the software had been opened which does not automatically mean that the content had been attempted each time. It was anticipated that some students may have opened the content and read the details surrounding the task and closed the application as they did not have sufficient time to complete it, thus registering an attempt. To avoid counting attempts of student who had not interacted with the software, students registering attempts and showing performance data were used. More exploration of the students' interaction with the asynchronous material needs to be made as the survey did not investigate the platform the students chose to complete the content or verify the number of attempts. Although it does highlight that offering academic skills asynchronously is accessible and students interacted with the material. 


\section{Impact on summative grade}

The largest difference in assessment grade was seen in the students who attempted e-tivities six or more times which could be down to students continuing to review the learning material which cemented their understanding. It also supports that the active classroom content is as important as the asynchronous content. Another explanation for the difference in summative grades when compared to those who did not attempt the e-tivities could be that those students who conformed to the teaching method are more motivated and studious regardless of the pedagogical approach.

Due to the placement of each session the research failed to demonstrate a significant difference between formative and summative grades. It is perceived that as the sessions incorporated skills to inform students' academic writing, the sessions helped to elevate the formative grade. Students are not clear of the boundaries or expectations of academic writing (Harwood and Hadley, 2004) therefore demystifying the expectations could have benefitted the formative scores.. The research showed that $66 \%(n=818)$ of attempts on the asynchronous resources were completed before the formative assessment submission date and $34 \%(n=421)$ of all attempts were completed between the formative and the summative submission date. The focus on the sessions were to inform students prior to the summative assessment using the formative assessment as the vehicle. However, the benefits to the formative assessment results have not been explored within the parameters of this research as there was not a valid benchmark embedded prior to the formative assessment. Other variables such as tutor feedback could have impacted on the summative grade with students gaining an understanding of the application of the academic skills as well as the flipped impact. Therefore, the research was not designed to suggest there would be a difference in the formative and summative grades.

\section{Academic confidence}

Although there was a decline in the number of attempts at each e-tivity as the e-tivities progressed this same relationship was not demonstrated in the academic confidence scores of students. This implies that although the attempts declined in number the perceived confidence levels gained remained static demonstrating that a third of students' perceived 
levels of confidence improved. The improvement of confidence could be a result of the pedagogical approach adopted in the research. This is further endorsed by Sander and Sanders' (2006) research which suggested that the university experience will affect selfesteem, and this will in turn affect academic performance. Having the confidence to succeed at higher education is important and using the flipped approach can only compliment academic skills teaching.

The success of the flipped approach was confirmed by most students (53.3\%) preferring a mixture of both online and face-to-face sessions to develop their academic skills. This agrees with the findings in a study by Pye et al. (2015) who found that $53 \%$ of students perceived that online systems maximised their classroom learning. The use of the flipped learning approach adopted for the research used software which was multifunctional and could be utilised pre, post, and during sessions (Harris, 2011). The inclusivity of the software (Hockings et al., 2012) was a benefit and the predominance of the text-based format (Harris, 2011) allowed transmission of academic skills content to be asynchronous which was later developed through the face-to-face sessions. The students who attempted a greater number of online activities and attended all sessions improved their confidence more than those who had engaged less. Interestingly, the confidence was gained more in the face-to-face sessions rather than the number of attempts on the asynchronous content. This suggests that if a student did not attend face-to-face sessions their perceived academic confidence was gained solely through the asynchronous content. The asynchronous content used to complement the flipped approach allowed students to control their learning habits and complete the tasks in their own time (Kamal and Radhakrishnan, 2019).

Delivering academic skills using the flipped approach relies on a change of culture. Freeman et al. (2014) suggest that active learning should be promoted as a preference rather than supporting an empirically validated practice, thus encouraging a culture which matures into a setting allowing students a comfortable environment to clarify information (Lage et al., 2000). This approach feels the most natural form to transmit academic skills. Rosinski and Peeples, (2012) found that active pedagogies which purposively integrate interaction between students and tutors are more likely to create successful academic writers. The aspects of this research did not explore the impact of the delivery method on retention but Freeman et al. (2014) 
suggest that this method positively affects retention with active learning classes holding onto a higher proportion of lower ability learners than traditional lectures.

\section{Conclusion}

This research explored the effectiveness of the flipped approach in delivering academic skills. The results found that students had a significantly higher summative score if they attended two or more sessions than those who attended 1 or less. The summative grades and the number of attempts for e-tivity 1 to 3 demonstrated a positive linear relationship. Overall, the academic confidence improved in nearly a third of all students for each e-tivity. This emphasises that the flipped approach is an effective method to improve summative grades and deliver academic skills. The content used asynchronously was meaningful and explored using a student-centred approach in the face-to-face sessions. The asynchronous material was active and had formative tasks to help students recall the information in the classroom. It was designed to be accessible and allow unlimited attempts. When designing academic skills asynchronously this research recommends that the content needs to be versatile and be able to be used both as a pre-learning and post-learning activity as students accessed this content in large numbers in both formats. It is also important that students see relevance in the activity therefore the research was designed to embed within curriculum and use subject specific content. This will then help promote attendance of the face-to-face sessions and compliance in completing the asynchronous content.

More research into the delivery of academic skills using the flipped approach within larger cohorts should be investigated. Additional recommendations from this research are that concept and expectations need to be explained to the cohort at the start of the module and subject specific content is used to deliver academic skills material. This will help to ensure adherence to asynchronous content and attendance at all face-to-face sessions which in turn could benefit the summative grades of students.

\section{References}


Abeysekera, L., and Dawson, P. (2014) 'Motivation and cognitive load in the flipped classroom: Definition, rationale and a call for research', Higher Education Research and Development 34(1), pp.1-14.

Appleton, L. (2005) 'Examination of the impact of information-skills training on the academic work of health studies students: a single case study', Health Information and Libraries Journal 22(3), pp.164-172.

Baepler, P., Walker, J. D. and Driessen, M. (2014) 'It's not about seat time: Blending, flipping, and efficiency in active learning classrooms', Computers and Education. doi: 10.1016/j.compedu.2014.06.006 [Accessed: 21 Oct 2019].

Bandura, A. (1977) 'Self-efficacy: Toward a unifying theory of behavior change', Psychological Review, 84, pp.191-215.

Bandura, A. (1997) Self-efficacy: The exercise of control. New York: Freeman.

Bartimote-Aufflick, K., Bridgeman, A., Walker, R., Sharma, M. and Smith, L. (2016) 'The study, evaluation, and improvement of university student self-efficacy', Studies in Higher Education, 41(11), pp.1918-1942.

Bergmann, J. and Sams, A (2007) Flip your classroom: reach every student in every class every day. Eugene: International Society for Technology in Education.

Bishop, J. and Verleger, M. (2013) 'Testing the flipped classroom with model-eliciting activities and video lectures in a mid-level undergraduate engineering course', Proceedings - Frontiers in Education Conference, FIE, pp.161-163. doi: 10.1109/FIE.2013.6684807 [Accessed: 21 Oct 2019]. 
Blythman, M. and Orr, S. (2002) 'Joined up policy: A strategic approach to improving retention in the UK context', Journal of College Student Retention 3(3), pp.231-242.

Carr, R., Palmer, S. and Hagel, P. (2015) 'Active learning: The importance of developing a comprehensive measure', Active Learning in Higher Education, 16(3), pp.173-186. doi: 10.1177/1469787415589529 [Accessed: 09 Dec 2019].

Chen, Y., Wang, Y., Kinshuk and Chen, N. S. (2014) 'Is Flip enough? Or should we use the flipped model instead?' Computers Education 79, pp.16-27.

Chevalier, A., Gibbons, S., Thorpe, A., Snell, M. and Hoskins, S. (2009) 'Students' academic self-perception', Economics of Education Review, 28. doi: 10.1016/j.econedurev.2009.06.007 [Accessed: 21 Oct 2019]

Chuthapisith, J., diMambro, B. and Doody, G. (2009) 'Effectiveness of a computer assisted learning (CAL) package to raise awareness of autism', BioMedCentre Medical Education 9(12), pp.1-6.

Chyr, W.L., Shen P. D., Chaing, Y.L., Lin, J.B. and Tsai, C.W. (2017) 'International forum of educational technology \& society exploring the effects of online academic help-seeking and flipped learning on improving students' learning', Source: Journal of Educational Technology \& Society, 20(3), pp.11-23. doi: 10.2307/26196116 [Accessed: 11 Nov 2019].

Dunning, D., Heath, C. and Suls, J. M. (2004) 'Flawed self-assessment implications for health, education, and the workplace', Psychological Science in the Public Interest, Supplement, 5(3), pp.69-106. doi: 10.1111/j.1529-1006.2004.00018.x [Accessed: 21 Oct 2019]

Fagard, R. H., Staessen, J. A. and Thijs, L. (1996) 'Advantages and disadvantages of metanalysis approach', Journal of Hypertension Supplement, 14(2), pp.9-12. 
Falchikov, N. and Boud, D. (1989) 'Student self-assessment in higher education: A metaanalysis', Review of Educational Research, 59(4), pp.395-430. doi: 10.3102/00346543059004395 [Accessed: 21 Oct 2019].

Farmer, R. (2018) 'The what, the how and the why of Flipped Classroom', Innovative Practice in Higher Education, 3(2), pp.14-31.

Fisher, C. D. (2017) 'Padlet: An online tool for learner engagement and collaboration', Academy of Management Learning \& Education, 16(1), pp.163-165. doi: 10.5465/amle.2017.0055 [Accessed: 08 Dec 2019].

Forsey, M., Low, M. and Glance, D. (2013) 'Flipping the sociology classroom: Towards a practice of online pedagogy', Journal of Sociology, 49(4), pp.471-485. doi: 10.1177/1440783313504059 [Accessed: 08 Dec 2019].

Freeman, S., Eddy, S.L., McDonough, M., Smith, M. K., Okoroafor, N., Jordt, H. and Wenderoth, M. P. (2014) 'Active learning increases student performance in science, engineering and mathematics', Proceedings of the National Academy of Sciences of the United States of America, 111(23), pp.8410-8415.

Garnham, W. A. and Betts, T. (2018) 'The padlet project: transforming student engagement in foundation year seminars', Compass: Journal of Learning and Teaching, 11(2). doi: 10.21100/compass.v11i2.714 [Accessed: 09 Dec 2019].

Gunn, C., Hearne, S. and Sitbthorpe, J. (2011) 'Right from the start: A rationale for embedding academic literacy skills in university courses', Journal of University and Learning Practice, 8(1), pp.1-12.

Hao, Y. (2016) 'Exploring undergraduates' perspectives and flipped learning readiness in their flipped classrooms', Computers in Human Behaviour, 59, pp.82-92. 
Hacker, D.J., Bol, L., Horgan, D. D. and Rakow, E. A. (2000) 'Test Prediction and Performance in a Classroom Context', Journal of Educational Psychology, 92(1), pp.160-170.

Harris, D. (2011) 'Presentation software: Pedagogical constraints and potentials', Journal of Hospitality, Leisure, Sports and Tourism Education 10(1), pp. 72-84.

Harwood, N. and Hadley, G. (2004) 'Demystifying institutional practices: critical pragmatism and the teaching of academic writing', English for Specific Purposes 23, pp. 355-377.

Hill, P. and Tinker, A. (2018) 'Making the second year count: embedding learning development in a progressive student journey', Journal of Learning Development in Higher Education, 10(14), pp.1-25.

Hitch, D., Goldingay, S., Hosken, N., Lamaro, G., MacFarlane, S., Nihill, C., Ryan, J. and Farrugia, D. (2012) 'Academic skills and beyond: a resource based approach to support student success in higher education', Journal of Academic Language and Learning, 6(2), pp.29-41.

Hockings, C., Brett, P. and Terentjers, M. (2012) 'Making a difference: inclusive learning and teaching in higher education through an open educational resource', Distance Education, 33(1), pp.237-252.

hooks, b. (2010) 'Teaching critical thinking: practical wisdom'. Abingdon: Routledge.

Jenson, J. L., Kummer, T. A. and Godoy, P.D.M. (2015) 'Improvements from a flipped classroom may simply be the fruits of active learning', Life Sciences Education, 14(5), pp.1-12.

Kamal, A. and Radhakrishnan, S. (2019) 'Individual learning preferences based on personality traits in an E-learning scenario', Education and Information Technologies, 24(1), pp. 407-435. 
Koohang, A., Floyd, K. and Stewart, C. (2011) 'Design of an open source learning objectives authoring tool: the LO creator', Interdisciplinary Journal of E-Learning and Learning Objects, 7, pp.111-123.

Lage, M. J., Platt, G. J. and Tregila, M. (2000) 'Inverting the classroom: a gateway to creating an inclusive learning environment', Journal of Economic Education, 31(1), pp.30-43.

MacVaughan, J., Jones, A. and Auty, S. (2014) 'Implicit, stand alone or integrated skills education for undergraduates: a longitudinal analysis of programme outcomes', Journal of further and higher education, 38(6), pp.755-772.

Mattern, K. and Shaw, E. (2010) 'A look beyond cognitive predictors of academic success: Understanding the relationship between academic self-beliefs and outcomes', Journal of College Student Development, 51(6), pp.665-678.

Munn, J. and Small, J. (2017) 'What is the best way to develop information literacy and academic skills for first year health science students? A systematic review', Evidence based library and information Practice, 12(3), pp.56-94.

Murray, N. and Nallaya, S. (2016) 'Embedding academic literacies in university programme curricula: a case study', Studies in Higher Education, 41(7), pp.1296-1312. doi: 10.1080/03075079.2014.981150 [Accessed: 06 Mar 2018].

Nicholson, L., Putwain, D., Connors, L. and Hornbe-Atkinson, P. (2013) 'The key to successful achievement as an undergraduate student: Confidence and realistic expectations?' Studies in Higher Eductaion, 38(2), pp.285-298.

Price, G. and Maier, P. (2007) Effective study skills, unlock your potential. Harlow: Pearson.

Price, R., Becker, K., Clark, L and Collins, S. (2011) 'Embedding information literacy in a first- 
year business undergraduate course', Studies in Higher Eductaion, 36(6), pp.705-718 doi: 10.1080/03075071003725350 [Accessed: 22 Oct 2019].

Pye, G., Holt, D., Salzman, S., Bellucci, E. and Lombardi, L. (2015) ‘Engaging diverse student audiences in contemporary blended learning environments in Australian higher business education: implications for design and practice', Australian Journal of Information Systems, 19, pp.1-20.

Reed, M.J., Kennett, D.J., Lewis, T. and Lund Lucas, E. (2011) 'The relative benefits found for students with and without learning disabilities taking a first-year university preparation course', Active Learning in Higher Education, 12(2), pp.133-142.

Rice, P., Beeson, P. and Blackmore-Wright, J. (2019) 'Evaluating the Impact of a Quiz Question within an Educational Video', TechTrends, 63(5), pp.522-532. doi: 10.1007/s11528-019-00374-6 [Accessed: 09 Dec 2019].

Rosinski, P. \& Peeples, T. (2012) 'Forging rhetorical subjects: Problem-based learning in the writing classroom', Composition Studies, 40(2), pp.9-33.

Ryan, R. M. and Deci, E. L. (2000) 'Self-determination theory and the facilitation of intrinsic motivation, social development, and well-being.', American Psychologist, 55(1), pp.6878. doi: 10.1037/0003-066X.55.1.68 [Accessed: 20 Sep 2019].

Salmon, G. (2013) E-Tivities. $2^{\text {nd }}$ edn. Abington: Taylor and Francis.

Sander, P. and Sanders, L. (2006) 'Understanding academic confidence', Psychology Teaching Review, 12(1), pp.29-41.

Smith, J., Groves, M., Bowd, B. and Barber, A. (2012) 'Facilitating the development of study skills through blended learning approach', International Journal of Higher Education, 1(2), pp.108-117. 
Strayer, J. F. (2012) 'How learning in an inverted classroom influences cooperation, innovation and task orientation', Learning Environments Research, 15(2), pp.171-193 doi: 10.1007/s10984-012-9108-4. [Accessed: 09 Dec 2019].

University of Nottingham (2008) The Xerte Project, University of Nottingham [online] Available at: https://www.nottingham.ac.uk/xerte/toolkits.aspx_ [Accessed: 25 May 2018].

Valentine, J. C., DuBois, D. L. and Cooper, H. (2004) 'The relation between self-beliefs and academic achievement: A meta-analytic review', Educational Psychologist, 39(2), pp.111-133 doi: 10.1207/s15326985ep3902_3. [Accessed: 22 Oct 2019].

van Hoorebeek, M., Walker, S. and Dermo, J. (2009) 'Analysing the parameters of the duty of reasonable adjustment to facilitate access to e-learning resources', Multicultural Education and Technology Journal, 3(3), pp.227-241. doi: 10.1108/17504970910984899 [Accessed: 24 Oct 2019].

Wilson, S.G.C. (2013) 'the flipped class: A method to address the challenges of an undergraduate statistics course', Teaching of Psychology 40(3), pp.193-199. 